\title{
Applying Margaret Newman's theory of health as expanding consciousness to psychosocial nursing care of HIV infected patients in Kenya
}

\author{
Kamau Simon Macharia ${ }^{1}$, Rotich Rose Jelagat ${ }^{1}$, Mwembe David Juma ${ }^{2}$ \\ ${ }^{1}$ University of Kabianga, Department of Nursing Sciences, P. O. Box 5, Kapkatet, 20214 Kenya \\ ${ }^{2}$ Kenya Medical Training College, Kapkatet Campus, Department of Nursing Sciences, P. O. Box 35, Kapkatet, 20214, Kenya
}

\section{Email address:}

symomash@gmail.com (Kamau S. M.), rose.rotich@yahoo.com (Rotich R. J.), dmmwembe@yahoo.com (Mwembe D. J.)

\section{To cite this article:}

Kamau Simon Macharia, Rotich Rose Jelagat, Mwembe David Juma. Applying Margaret Newman's Theory of Health as Expanding Consciousness to Psychosocial Nursing Care of HIV Infected Patients in Kenya. American Journal of Nursing Science. Special Issue: Mental Health Care: Aspects, Challenges and Perspectives. Vol. 4, No. 2-1, 2015, pp. 6-11. doi: 10.11648/j.ajns.s.2015040201.12

\begin{abstract}
Margaret Newman's Theory of Health as Expanding Consciousness is considered a grand nursing theory, she described a process of becoming more of oneself, of finding greater meaning in life, and of reaching new dimensions of connectedness with other people and the world. Nurses in Kenya have mostly used the psychosocial-medical model to nurse HIV infected patients which fails to answer many of the nursing concerns and reduces their autonomy in carrying out nursing care. Newman's theory proposed that: Health is not lack of illness, or a process to become healthy from being ill, but it instead the expansion of consciousness as a result of choices made within the context of patterns of behavior. Methodology: This mini review was an evolving emergent design. Slightly adapted 'Advanced Theory in Nursing' coursework materials were used. The greatest resource were referrals to links and hints as offered by those who got interested in the study. A best case scenario is appended. Conclusion: Newman's Theory of Health as Expanding Consciousness is therefore a generic tool applicable to guide psychosocial nursing care of clients infected with HIV. It would be a great resource with a potential to evidence based nursing care. It would provide a basis for several case studies. Nurses find more fulfilment in their work by utilizing a nursing theory.
\end{abstract}

Keywords: HIV, AIDS, Margaret Newman, Health as Expanding Consciousness, Psychosocial, Walter Reeds Project, Kenyan Nurses, Nursing Theory

\section{Background}

Anecdotal evidence shows that nurses involved in the care of HIV infected patients in Kenya have mostly used the psychosocial-medical model whose primary focus is on the diagnosis and treatment of symptoms and disease. This fails to answer many of the nursing concerns and reduces their autonomy in carrying out nursing care. For example many HIV-infected persons have high levels of depressive symptomatology, as well as suicidal ideation and hopelessness being increasingly reported, usually upon knowing their seropositive status or precipitated by progression of the illness [1]. How would the nurse best handle these concerns? A Theory (or a combination of theories) might come as a handy relief.

\section{Why Theory}

Everyday practice enriches theory and vice versa as both practice and theory are guided by values and beliefs. Theory helps to reframe our thinking about nursing and guides use of ideas and techniques. Theory can close the gap between theory and research and envision potentialities. "The study and use of nursing theory in nursing practice must have roots in the everyday practice of nurses" [2]. It guides nursing practice and generates knowledge, it helps to describe or explain nursing, it enables nurses to know WHY they are doing WHAT they are doing [3] and enhance evidence based nursing. Another example might be why health-supporting activities inside the hospital can be carried on outside the hospital [4].What evidence, best practices (including theories) are there that would support this?

"Practicing nurses who despise theory are condemned to 
performing a series of tasks - either at the command of a physician or in response to routines and policies", an observation made by Leah Curtin, a former editor of Nursing Management [5]. Newman on the other hand showed the necessity of linking practice with theory by saying, "We have to embrace a new vision of health. Our caring must be linked with a concept of health that encompasses and goes beyond disease". The theory of health as an expanding consciousness provides this link.

As we introduce this theory it's good to recognize that Patient-as-person involves an appreciation for the patient's self-perception and expression of an illness and the recognition that the patient's illness is a unique experience, one that is influenced by the patient's attitudes, knowledge, and current personal or social context [6]. Two patients can have varied responses to the same illness or chronic condition due to their personality, different life experiences and circumstances. These are some of the reasons why nurses need to use a nursing theory in patient care.

According to Polit referred to in [7], 'Theory is the ultimate aim of science: It transcends the specifics of a particular time, place, and group and aims to identify regularities in the relationships...' A statement by College of Nursing of University of Colorado Denver, Guidelines for Evaluating Published Research Reports (NURS 6031) Themes or Rules-Of-Thumb, item number 11 states that: 'Other things being equal, research related to theories is more important than non-theoretical research'.

\section{Theory of Health as Expanding Consciousness}

Margaret Newman's Theory of Health as Expanding Consciousness (HEC) posits that "every person in every situation, no matter how disordered and hopeless it may seem, is part of the universal process of expanding consciousness a process of becoming more of oneself, of finding greater meaning in life, and of reaching new dimensions of connectedness with other people and the world" [8].

Newman wanted to move from the reductionist model of 'health is the absence of disease', and develop a model that would articulate the essence of nursing practice. Health within illness dichotomy may not be a readily accepted concept. This theory considers illness as an opportunity for awareness and growth. 1t also shifts the focus of health care from fighting the enemy of illness to learning about oneself through the illness experience.

The concept of consciousness as defined by Newman is the informational capacity of the system (in this case, the human being); that is, the ability of the system to interact with the environment. Consciousness includes not only the cognitive and affective awareness that is normally associated with consciousness, but also the inter-connectedness of the entire living system that includes physiochemical maintenance and growth processes as well as the immune system [8].

\section{Assumptions}

Newman held the view that Health as an Expansion of Consciousness (HEC) is based on five assumptions [9]:

1. Health encompasses conditions previously viewed as pathology,

2. "pathology" can be a manifestation of the total pattern,

3. Pathology may exist as a manifestation of a pattern that exists prior to the manifestation of physical or structural changes (manifesting as pathology),

4. Removal of the pathology does not change the pathology, and

5. "Illness" maybe be the only way an individual's pattern can manifest, and as such that is health for that individual We wanted to add a sixth assumption that, 'The tension in illness can allow patterns of expanding consciousness to emerge'.

\section{Concepts}

Some of the concepts of this theory are;

'The theory of health as expanding consciousness (HEC) was stimulated by concern for those for whom health as the absence of disease or disability is not possible'. Nurses often relate to such people: people facing the uncertainty, debilitation, loss and eventual death associated with chronic illness'.

The theory has progressed to include the health of all persons regardless of the presence or absence of disease -asserts that every person in every situation, no matter how disordered and hopeless it may seem, is part of the universal process of expanding consciousness - a process of becoming more of oneself, of finding greater meaning in life, and of reaching new dimensions of connectedness with other people and the world [10].

\section{Propositions}

The theory proposed that: Health is not lack of illness, or a process to become healthy from being ill, but it instead is the expansion of consciousness as a result of choices made within the context of patterns of behavior. Although this theory can be abstract and challenging to grasp, one of the main strengths of this model is that it addresses the patient and their choices, experiences and state of health (and unhealth) as a whole [11].

\section{Application to Practice}

Kenya has been battling with HIV/AIDS since it was recorded in 1984, HIV infection has spread very rapidly in the country and the magnitude and impact of HIV/AIDS is a major public health and development challenge. To date it is estimated that more than 2.2 million Kenyans are infected with HIV and that over 1.5 million Kenyans have died of AIDS and AIDS related illnesses. In Kenya the HIV infection rates are at $5.4 \%$ with some counties like Homa Bay 
recording as high as $14 \%$ of their population as having the virus [12]. Estimates show that the undiagnosed figures could be higher.

A diagnosis of HIVAIDS can be devastating to persons and their families as they face a multitude of physical, emotional, spiritual and social stresses from the effects of treatment, changes in lifestyle, disruption of home and family roles, and fears of stigma. People infected with HIV are challenged by changes in their endurance and strength, reproductive capacity, sexuality and self-image, as well as their own mortality.

For the newly diagnosed HIV positive client just as Newman referenced in [13] they learn that "each day is precious and that the time of one's life is contained in the present." Stigma has to be fought and that simply having a disease does not make a person unhealthy. One could experience health and wholeness in the midst of having a chronic and progressive disease, before and even after CD4+ $\mathrm{T}$ cells levels prognostic indicators signify need to initiate ARTs and opportunistic infections (OI's) medications.

We tended to relate this with Martha Rogers (Newman stated that Roger's theory of Unitary Human Beings was the main basis of the development of her theory) who had said earlier that health and illness may not be two separate realities, but rather as a unitary process. Rogers' Science of Unitary Human Beings puts the key thesis of the model as: The individual is a unified whole in constant interaction with the environment; nursing helps individuals achieve maximum well-being within their potential... in that people can experience health even when they are physically or mentally ill.

Nursing must find ways to care creatively for patients. Holistically to encompass the whole person, not just a body part or system. We need to emphasize this at every opportunity and during their appointments to the Comprehensive Care Centers (CCC). Indeed health is not the opposite of illness, but rather health and illness are both manifestations of a greater whole. One can be very healthy in the midst of a terminal illness as long as they maintain a healthy mind-set, positive self-image, eat well, involve in social support, avoid reinfection and adhere to treatment among others. We have a saying here in Kenya that, 'One is either infected or affected by HIV'. At least every Kenyan knows someone who has it. In some regions of this country people know entire households that have been wiped by the virus. Not long ago it was not possible for people to own up in public disclosures about their seropositive status. We now have people living with HIV (PLWHA) for over 25 years and are apparently healthy. Discordant couples are still a big dilemma for us even as we endeavor to move towards elimination of mother to child transmission of HIV (eMTCT) in sub-Saharan Africa by December, 2015[14].

An important realization by Newman was that (orientation to- emphasis mine) time, movement, and space were in some way interrelated as parameters of health. Every remaining faculty must be appreciated especially during the times of diminishing health or terminal stages. Some people have realized new strengths unknown to them before the diagnosis with terminal illnesses, one Asumpta Wagura has achieved exponential feats [15]. Her motto goes like 'Do not take life for granted. Celebrate it'. She has been a beacon of hope for people living with HIV/AIDS (PLWHA). She is the Executive Director of Kenya network of women with AIDS (KENWA). Many people look forward to her diary in Wednesday's edition of Daily Nation, Kenya's leading newspaper.

Time is a treasure for the HIV infected persons, they can make a choice on how best to use it to gain maximum returns in terms of their future and that of their children by making realistic goals based on the life expectancy. Increased insight into the meaning of their experience and the meaning of health can be realized when the client and the carer(s) connect in their new roles in health during counselling and social support.

The theory applies to the nursing today because of the increasing emphasis on continued care outside of the hospital. Whereas health-supporting activities inside the hospital can be carried on outside the hospital, a lot of social support and empowerment is needed. Home-based care has been shown to reduce the workload of the health care providers and lowers the economic burden of rural/local health care centres to care for HIV/AIDS patients [4]. But home-based care as taught in nursing curriculum is a new concept in Kenya although it has always been practiced in the African traditional cultures. The patient needs to be psychologically prepared for the recovery at home and to accept this as part of his/her medical/nursing history now. Helping them understand that this is not temporary but will be the norm will help them get the available resources they need to function. While home nursing does not seem readily appealing to the nurses in Kenya, it would in a big way '...bring out the significant caring manner witnessed by the power of nursing presence in the patient's usual surroundings' as was proposed by Newman.

The patient needs to acknowledge the issue before anything can be done about it. Acknowledging and accepting it will lead to this new wonderful consciousness (expanding consciousness) where help can enter the patient's life. In this new consciousness, the nurse needs to involve the patient in the nursing care plan. Define what their goals are, whether they are new or still the same goals, and how to get there. Newman talked about making deliberative observations about patients and reflecting what she observed back to the patient. This specific attention stimulates patients to respond by talking about what was meaningful in their unique circumstances and their subtle needs. From our experience(s) and as seen in the case study below, HIV infected persons really appreciate this: they wish to connect with self, interpersonal and the community in a holistic sense to achieve a greater sense of health. The point is; if you can get a patient to identify their goals and then give them tools to achieve those goals, that patient can continue to help him/herself and "transcend" their current state, adds Newman.

The meaning of the new seropositive status and illness will 
need to be understood within the context of the patient's entire life, not just his/her physical state (whether ill or just HIV positive). This way a path towards health becomes apparent to the patient. The eventuality (about full blown AIDS) can be postponed but it will catch up with time. The patient will be prepared in advance on what to expect as CD4+ T cells counts start going down significantly and AIDS sets in '... and if becoming "ill" is the only way a person's pattern can be manifested, then be it! That is health for the person' adds Newman. This process of focusing on meaning in patients' lives to understand where the current health predicament fits in the whole of people's lives has endured as central to the Theory of Health as Expanding Consciousness. We felt that the following Newman's quote, though a paradox in light of public health, holds some truth;

"[t]he responsibility of the nurse is not to make people well, or to prevent their getting sick, but to assist people to recognize the power that is within them to move to higher levels of consciousness" [12].

There is an increasing interest in personal transformation during illness. Case studies from clinical practice illustrate the potential contribution of 'shared consciousness' or..... For Newman, disease is a meaningful reflection of the whole and health is 'expanding consciousness' in assisting people to use the power within them. The two (illness and health) are thus seen as a continuum.

\section{Case Study Mrs Y.}

Utilizing Margaret Newman's theory through a case of a family experience of HIV/AIDS in Kenya "This is a case of Mrs.Y, a 32-year-old female, a resident in the Kericho County in south rift region of Kenya. She is a housewife and the husband is a small scale farmer. She is married a mother to eight (8) children; four boys and four girls, all alive. She tested HIV positive in 2002 but the husband is HIV negative to date. She started using antiretroviral (ARV) drugs eight years ago when her CD4's were 250. The family has been enrolled with Walter Reed Project (an NGO Supporting HIV/AIDS patients- through, counselling, testing, medication and food Supplements for free. The project is a partner with PEPFAR- Presidential Emergency Plan for AIDS Relief).

The rest of the children are negative apart from the last born who is seven months old and now sickly. All the 8 children were born in hospital, 4 after they knew their status. Mrs Y. has been in and out of hospital since 2006 with complains of chest congestion, oedema, difficulty in breathing and fatigue. Most notably her health has been down with every subsequent pregnancy. On the other hand, Mr.Y has been undergoing a series of regular laboratory tests but remained HIV Negative. The couple verbalized appreciating their support for one another despite their status view life positively for the sake of their children who are unaware of the health status of either of their parents. Furthermore the health care team have been helping them especially when they are admitted.
The nurse at the Comprehensive Care Centre utilized the components of Margaret Newman's Theory of Health as Expanding Consciousness to assist Mrs. Y. in pattern recognition so she may understand new possibilities for action; that in illness, there is room for health. Expanding consciousness around her illness helped her see that within the confines of her disease, she could enjoy aspects of health. Illness was not something that "happened to her", but was a part of her life's pattern.

Nurses have had wider role since they are with the patient every other time which enabled them to win the couples' trust and confidence leading to a therapeutic nurse-patientrelationship over the years. Weekly visits by a home-care nurse includes- assessments of her weight, blood pressure, $\mathrm{B}_{12}$ injections and reviewing medication adherence. The home-care nurse also identified potential for increased interaction with others and an increase in consciousness by triggering understanding of new possibilities for action. To recognize past patterns of relating and how present circumstances have changed those patterns.

Something interesting the couple once said was ' ...the best medication for patient with human immunodeficiency virus/acquired immune deficiency syndrome is acceptance of the status'. They added nutrition and adherence to antiretroviral medication regimens as very important. They recognized psychosocial support as a means of coping among those with HIV/AIDS, Mrs Y. belongs to a peer group, she says '....it has proved to be thoroughly effective'. Previously she had also felt that she did not want to 'feel like a burden' to anyone. However she adds that most of her long-time friends have since passed away, she says these were mainly those with very little social exchange.

Mrs Y. represents over 2.2 million people Kenya living with HIV/AIDS (PLWHA). Kenya's population was 40 million people by 2009 census. An early step for the discordant couple in HIV preventive counselling on behavioral risk assessment was done to the couple as high risk individuals.

Her health has taken a nose dive in the last few months. She has become debilitated and sick with side effects from ART therapy. She is unable to work, play with her children or keep up the chores around their home. Were it not for the help they get from the Walter Reeds all their financial resources were but exhausted, they were running low on all including groceries.

She said she was able to face her death with pride and dignity. She felt that she had continued to live and enjoy her children as much as possible. She had provided real hope and encouragement to others experiencing a HIV/AIDS diagnosis. She made the following comment close to her death, "I may be dying of AIDS, but I feel healthier than I have ever felt".

\section{The Future}

We saw from Margaret Newman's various writings on Theory of Health as Expanding Consciousness [10, 13, 17] posits that humans cannot be divided into parts, but are 
inextricably whole beings. Health is central to the theory "and is seen as a process of developing awareness of self and the environment". That "Consciousness is a manifestation of an evolving pattern of person-environment interaction" and that consciousness is an ongoing process.

We felt that the theory of Health as Expanding Consciousness (HEC) helps direct nursing in supporting patients of today and if integrated with current social media technologies like Web 2.0, will be one that will prove useful well into the future. For example a social platform "Patients Like Me" [16] was designed to help patients encourage others beginning the journey, find support with others who were dealing with similar conditions. Taking HEC literally, these technologies really can support patients in "finding greater meaning in life and of reaching new dimensions of connectedness with other people and the world". Nursing can help patients navigate to such resources that will support them through their health experiences. Theories like Dr. Newman's will offer direction on how to find consistency in supporting patients in an ever changing landscape of knowledge and care.

\section{Conclusion}

Margaret Newman's Theory; expanding consciousness is a process wherein an individual becomes more of his/her real self, as he/she finds greater meaning in his/her life and the lives of those people around him/her. Self-awareness may eventually lead to acceptance of one's self and one's circumstances and limitations. Newman's theory of pattern recognition provides the basis for the process of nurse-client interaction. She suggested that the task in intervention is a pattern recognition accomplished by the health professional becoming aware of the pattern of the other person by becoming in touch with their own pattern. Humans cannot be divided into parts, but are inextricably whole beings. Health is central to the theory "and is seen as a process of developing awareness of self and the environment" (Newman, 2010). "Consciousness is a manifestation of an evolving pattern of person-environment interaction" (Newman, 2013).This consciousness is an ongoing process.

Therefore, we submit that Margaret Newman's Theory of Health as Expanding Consciousness (HEC) is a generic tool that would be applicable to psychosocial nursing care of clients with HIV in Kenya and elsewhere. It is therefore a great resource. Several case studies based on this model would be possible. Nurses would find more fulfilment in their work by utilizing a nursing theory. Hopefully, readers will be directed to seek further information, some of which are contained in the links below in order to fully appreciate the utility value of this approach to nursing care. A home page referred in [17] would be a great place to refer. Nurse Managers in charge of nursing units (including CCC's) are encouraged to consider adopting on a minimum one relevant nursing theory/model $[18,19]$ as a step towards evidence based practice. On a minimum it is not hard to think of an experience where the theory could have been applied. More importantly how accessible (even in terms of understanding) HEC is to you? How can it benefit your practice?

\section{Acknowledgment}

We are so grateful to the client's family for allowing us to use their case study. The authors had hoped that Mrs. Y. would be alive by the time of making this presentation and we would have appended the case study instead of making it part of the main article.

"S.M.K" thanks the students, presenters and discussants (2014, Spring Semester). Lecture notes and presentations. NURS 6012: Advanced Theory in Nursing. University of Colorado Denver, USA.

\section{References}

[1] Govender R. and Schlebusch L. Hopelessness, depression and suicidal ideation in HIV-positive persons. South African Journal of Psychiatry 2012; 18; No 1

[2] Alligood, M. R. Nursing theorists and their work. Elsevier, Mosby 2014: 442-463.

[3] Gordon, Parker, and Jester "Theories of nursing practice: Lecture notes and presentations". Delmar Learning, a division of Thomson Learning 2001. Retrieved on 12th March 2014.

[4] Halie B. Affordability of Home-Based Care for HIV/AIDS. South Africa Medical Journal 2000; 90 (7): 690-691.

[5] Leah Curtin. "Performance edge". Nursing Management1989; Vol. 20(6). Retrieved from: http://faculty.mercer.edu/stewart_dj/Web\%20Pages/Nurse\%20 Theory\%20Module.ppt

[6] Mead, N., \& Bower, P. "Patient-centeredness: A conceptual framework and review of the empirical literature". Social Science and Medicine 2000; Vol. 51: 1087-1110.

[7] Polit, D.F., \& Beck, C.T. Nursing research: Generating and assessing evidence for nursing practice (9th ed.), Philadelphia: Lippincott, Williams, and Wilkins 2012.

[8] Newman, M. "Newman's Health as Expanding Consciousness" 2013. Retrieved: http://currentnursing.com/nursing_theory/Newman_Health_A s_Expanding_Conscious

[9] Newman, M. Transforming presence. Philadelphia, PA: F. A. Davis. 2008.

[10] Newman, M. Health as expanding consciousness. National League of Nursing. New York 1994. Retrieved: http://www.healthasexpandingconsciousness.org/home

[11] Lecture notes and presentations by Sage Mehew et al., (student presenters and discussants) to Geer Betty PhD. (2014, Spring Semester).NURS 6012: Advanced Theory in Nursing. University of Colorado Denver, USA.

[12] Kenya AIDs Indicator Survey- KAIS, 2014.

[13] Parker, M. \& Smith, M. Nursing theories and nursing practice (3rd ed.). F. A. Davis Company. Philadelphia 2010, p290-313. 
[14] Born Free. Initiative to end mother-to-child transmission of HIV in Africa by December 31 ${ }^{\text {st }}$, 2015. (2014). Retrieved: http://bornfreeafrica.org/,

http://bornfreeafrica.org/BORNFREE_BLC.pdf

[15] Living with purpose | wamakeri https://wamakeri.wordpress.com/tag/living-with- purposel Assumpta Wagura's Diary, Wednesday Daily Nation.

[16] Patients Like Me: http://www.patientslikeme.com/
[17] Home http://www.healthasexpandingconsciousness.org/home

Page

[18] Yang, A., Xiong, D., Vang, E., \& Pharris, M. Hmong American women living with diabetes. Journal of Nursing Scholarship. 2009; 41, 139-148.

[19] Papathanasiou I., Kourkouta L., Sklavou M. Holistic Nursing Care: Theories and Perspectives. American Journal of Nursing Science $2013 ; 2$ (1): 1-5. 